\title{
Membrane Properties and Discharge Characteristics of Guinea Pig Dorsal Cochlear Nucleus Neurons Studied in vitro
}

\author{
Paul B. Manis \\ Departments of Otolaryngology-Head and Neck Surgery, Neuroscience and Biomedical Engineering, The Johns Hopkins \\ University School of Medicine, Baltimore, Maryland 21205
}

Intracellular recordings were made from neurons of the guinea pig dorsal cochlear nucleus in an in vitro brain slice preparation. The membrane properties of the cells were studied, and the membrane potentials were manipulated by current injection to determine how intrinsic conductances might alter the cell discharge patterns. Eleven cells were marked with Lucifer yellow. Ten of these cells were identified as the large pyramidal cells of layer 2 of this nucleus, and 1 cell was identified as a "vertical" cell in layer 3. Two kinds of action potentials were observed: simple spikes and complex spikes. This report discusses only cells with simple spikes. Simple spiking cells $(60 / 72$ recorded cells; all stained cells were simple spiking cells) discharged in a regular fashion with depolarization, and had linear frequency-current relationships up to $2 \mathrm{nA}$ with a mean slope of $116 \mathrm{~Hz} / \mathrm{nA}$. The discharge rate was approximately constant throughout the current pulse. Responses of simple spiking cells to depolarizing current steps superimposed on a steady-state membrane hyperpolarization were studied. When the membrane has been held hyperpolarized, small current pulses produce a long-latency regular train of action potentials. Larger current pulses superimposed on membrane hyperpolarization can produce a short-latency action potential followed by a long silent interval (i.e., a long first interspike interval), and finally a regular train of spikes. It is concluded that the membrane conductances of DCN pyramidal cells are capable of generating at least 3 discharge patterns (regular firing, long first spike latency, and long first interspike interval) depending on the state of the membrane potential prior to a depolarizing current step. These responses are similar to the "chopper," "buildup," and "pauser" discharge patterns reported for these cells in vivo in response to tone bursts. The modulation of the intrinsic membrane conductances by membrane polarization and the possible contribution of these

\footnotetext{
Received Oct. 2, 1989; revised Mar. 14, 1990; accepted Mar. 20, 1990.

I would like to thank the members of the Center for Hearing Sciences at Johns Hopkins University, as well as the thoughtful reviewers that read and made valuable comments on the manuscript. I would also like to thank Dr. Kenna Peusner for bringing to my attention the Grace and Llinas (1985) paper, and Ms. Cori Strathmeyer for histological preparation. This material is based upon work supported by the National Science Foundation under Grant BNS 8607273 and the National Institute for Deafness and Other Communicative Disorders Grant DC00425.

Correspondence should be addressed to Paul B. Manis, Department of Otolaryngology-Head and Neck Surgery, The Johns Hopkins University School of Medicine, 424 Traylor Research Building, 720 Rutland Avenue, Baltimore, MD 21205 Copyright (C) 1990 Society for Neuroscience $0270-6474 / 90 / 072338-14 \$ 03.00 / 0$
}

conductances to the generation of DCN discharge patterns provide new insights into the mechanisms underlying the responses of DCN cells to acoustic stimuli.

Sensory stimuli are encoded by the CNS in the temporal discharge patterns of single neurons and in the spatial patterns of activity of ensembles of neurons. Temporal encoding is controlled by intrinsic voltage-dependent membrane conductances of neurons and by the timing of convergent synaptic inputs. It has been demonstrated in the mammalian CNS that many features of the temporal activity of cells can be replicated by appropriate activation of specific membrane conductances, even in the absence of interacting networks of cells (Llinás, 1988). Complex patterns of activity similar to those recorded in vivo can be evoked with appropriate current injection in single thalamic, cerebellar, or inferior olivary cells in vitro (Llinás and Sugimori, 1980; Llinás and Yarom, 1981; Jahnsen, 1986a; Hounsgaard and Midtgaard, 1988; Llinás and Mühlethaler, 1988). In the auditory system, stellate cells of the ventral cochlear nucleus fire in a regular, repetitive fashion in part because of their intrinsic membrane conductances (Oertel, 1983; Wu and Oertel, 1984). This regular firing pattern is similar to that recorded from identified stellate cells in vivo (Rhode et al., 1983a; Rouiller and Ryugo, 1984). In this paper, I demonstrate that neurons of the dorsal cochlear nucleus (DCN) also have intrinsic membrane conductances which drive the cells towards specific discharge patterns similar to those that have been reported in vivo for responses to tones.

DCN neurons respond to acoustic stimuli with complex temporal discharge patterns (Pfeiffer, 1966; Goldberg and Brownell, 1973; Godfrey et al., 1975; Van Gisbergen et al., 1975; Adams, 1976; Shofner and Young, 1985; Rhode and Smith, 1986; Rhode and Kettner, 1987). These temporal patterns are different from those of the auditory nerve fibers (Kiang et al., 1965) that provide 1 of the major excitatory inputs to DCN cells (Osen, 1970; Cohen et al., 1972; Jones and Casseday, 1979; Kane, 1974a, b; Manis and Brownell, 1983; Moore, 1986). The temporal features of the DCN cell responses have been studied using peristimulus time histograms (PSTH) and classified as "pauser," "buildup," "onset," "on-off," and "chopper" responses. While cochlear nucleus cells have often been classified by their responses to best-frequency tone bursts, many cells can generate more than onc of thesc discharge patterns depending on the frequency and intensity of the tonal stimulus (Goldberg and Brownell, 1973; Godfrey et al., 1975; Adams, 1976; Rhode and Kettner, 1987). The PSTH responses "pauser," "buildup" and "on-off' are found almost exclusively in the DCN, indicating that coding of acous- 
tic stimuli in this nucleus is different from that occurring in other regions of the cochlear nucleus.

Intracellular recordings from DCN cells in barbiturate anesthetized cats have shown that the silent periods in responses to acoustic stimuli are not necessarily associated with hyperpolarization of the cell membrane potential (Gerstein et al., 1968; Starr and Britt, 1970; Britt and Starr, 1976; Romand, 1978; Rhode et al., 1983b; Rhode and Smith, 1986). In order to explain these results, it has been proposed that either the recordings were made some distance from the site of action potential generation, so that the membrane events that controlled the discharges were not observed (Gerstein et al., 1968; Starr and Britt, 1970) or that the silent periods in the cell discharge were produced by presynaptic inhibition (Britt and Starr, 1976). In addition, since some of these recordings were made with potassium chloride electrodes, failure to observe hyperpolarization during the silent episodes could reflect a disturbed chloride equilibrium potential. Conversely, Rhode et al. (1983b, 1986) noted that intracellular penetration could change the response patterns of some DCN cells relative to extracellular recordings, presumably from the same cells, and that hyperpolarization of the cell could restore the original extracellularly recorded pattern. This observation suggests that the resting membrane potential of the cell plays an important role in the generation of the response pattern and raises the possibility that intrinsic membrane conductances of DCN cells are in part responsible for the observed discharge patterns to acoustic stimuli.

The intrinsic membrane properties of DCN cells were first investigated by Hirsch and Oertel (1988a) in an in vitro slice preparation from the mouse. They found that all cells which exhibited simple spikes discharged regular trains of action potentials when depolarized from rest, i.e., a "chopper"-like response pattern. In addition to the usual fast inactivating $\mathrm{Na}^{+}$ and noninactivating $\mathrm{K}^{+}$(delayed rectifier) conductances that generate action potentials, they presented evidence for a transient (high-threshold) calcium conductance and a slowly activating TTX-sensitive inward rectifier. Conductances sensitive to the extracellular application of 4-aminopyridine (4-AP) and muscarine were also revealed.

The present study investigates the role of intrinsic membrane conductances of DCN neurons in the generation of their discharge patterns. The responses of DCN cells to intracellularly injected current steps have been studied in a guinea pig brain slice preparation. In this paper, the membrane and discharge patterns of the simple spiking cells are characterized. Simple spiking cells stained with Lucifer yellow were found to be primarily pyramidal cells. Steady-state membrane hyperpolarization was found to alter the cell response to subsequent depolarization, resulting in discharge patterns resembling those found in vivo in response to acoustic stimuli. These results suggest that intrinsic membrane conductances other than those generating the action potential may contribute to the discharge patterns of DCN cells. Some preliminary results of these studies have been reported (Manis, 1988a, b).

\section{Materials and Methods}

Slice preparation. Slices from guinea pig brain were prepared as previously described (Manis, 1989). Briefly, pigmented guinea pigs weighing 250-400 gm were anesthetized with Nembutal $(35 \mathrm{mg} / \mathrm{kg})$, decapitated, and the brain stem quickly dissected out. The brain stem was washed in room temperature $\left(21^{\circ} \mathrm{C}\right)$ HEPES-buffered saline, the cochlear nucleus and adjoining brain stem isolated with scissor cuts, and 350 $\mu \mathrm{m}$ sections through the dorsal cochlear nucleus cut with an oscillating tissue slicer. Slices were cut in either the strial-transverse plane, i.e., parallel to the long axis of the DCN in the transverse direction (Manis, 1989), or orthogonal to this plane, in a "transstrial" axis in which the rostral end of the slice is tilted dorsally $20^{\circ}-30^{\circ}$ from the horizontal plane (Blackstad et al., 1984). The transstrial axis is approximately parallel to the isofrequency planes of the nucleus. The slices were incubated for $1-2 \mathrm{hr}$ in a bicarbonate buffered saline at $31^{\circ} \mathrm{C}$ before transfer to the recording chamber. In the recording chamber, the slice is gently held between 2 nets and superfused with the bicarbonate-buffered saline at a rate of $3-5 \mathrm{ml} / \mathrm{min}$. The temperature in the recording chamber is $31-33^{\circ} \mathrm{C}$.

Solutions. The HEPES-buffered solution used during brain dissection and slice preparation contains (in $\mathrm{mM}$ ) $134 \mathrm{NaCl}, 5 \mathrm{KCl}, 1.25 \mathrm{KH}_{2} \mathrm{PO}_{4}$, 10 glucose, $10 \mathrm{HEPES}$ buffer, $0.2 \mathrm{CaCl}_{2}$, and $4.0 \mathrm{MgSO}_{4}$, and is brought to $\mathrm{pH} 7.35$ with the addition of approximately $2 \mathrm{~mm} \mathrm{NaOH}$. The dissection solution is equilibrated at room temperature with $100 \% \mathrm{O}_{2}$. The bicarbonate-buffered incubation and recording solution contains (in $\mathrm{mM}$ ) $130 \mathrm{NaCl}, 3 \mathrm{KCl}, 1.25 \mathrm{KH}_{2} \mathrm{PO}_{4}, 20 \mathrm{NaHCO}_{3}, 10$ glucose, $2.5 \mathrm{CaCl}_{2}$, and $1.3 \mathrm{MgSO}_{4}$. This solution is warmed to $34^{\circ} \mathrm{C}$ in temperature-controlled water baths, and is equilibrated with $95 \% \mathrm{O}_{2}-5 \% \mathrm{CO}_{2}$. The $\mathrm{pH}$ is between 7.35 and 7.40 .

Recordings. Intracellular recordings were made with fine-tipped glass micropipets filled with $3 \mathrm{~m}$ potassium acetate (in some cases with an additional $5 \mathrm{~mm}$ potassium chloride) or $0.125-0.250 \mathrm{M}$ lithium chloride with $8 \%$ Lucifer yellow. Pipets were pulled in 2 stages to produce a rapid taper $(\sim 2 \mathrm{~mm})$. Only electrodes with impedances between 40 and $80 \mathrm{M} \Omega$ when filled with 3 м KAc or 80-150 M $\Omega$ when filled with Lucifer yellow were used. Electrodes were advanced into layer 2 of the DCN under visual control. This layer could be identified by the characteristic patterns of myelinated fibers just superficial to the layer and the more densely myelinated (and therefore more opaque) regions of layer 3 . The electrode resistance was continuously monitored with a short current pulse of $-200 \mathrm{pA}$. When the apparent electrode resistance increased, a weak oscillating current (buzz) or a 10-20 nA positive current pulse was passed through the electrode for $10-20 \mathrm{msec}$. The buzz or current pulse sometimes resulted in the penetration of a cell.

Recorded cells could be divided into 2 classes on the basis of spontaneous activity and the holding current necessary to stop spontaneous activity. Some cells had little or no spontaneous activity, and so required less than $0.1 \mathrm{nA}$ of holding current to silence the cell. Thirty-six cells fell into this class. Thirty-six other cells exhibited a spontaneous firing rate of $20-50 \mathrm{~Hz}$. Because of the high spontaneous rate there was no time at which the cell membrane potential was at "rest." Therefore, to facilitate the analysis of current-voltage relationships and cell discharge characteristics, a hyperpolarizing holding current of less than $1.0 \mathrm{nA}$ ( $<1.5 \mathrm{nA}$ when Lucifer yellow-filled electrodes were used) was used to silence the spontaneous activity. When the holding current was turned off, these cells usually resumed their spontaneous activity with a rate of $20-50 \mathrm{~Hz}$. In cells studied with holding current, the current was only that amount necessary to stop the spontaneous activity. Measurements of the cell properties were then made at this holding level. This membrane potential is referred to as the holding potential for spontaneously active cells, while the term resting potential is reserved for those cells with sufficiently low rates of spontaneous activity that a true resting level could be determined. Cells studied with and without holding currents showed similar input resistances, membrane time constants, spike amplitudes, and average recording duration. Cells which required more than $1.0 \mathrm{nA}$ holding current often exhibited signs of damage such as small action potential amplitudes or unstable membrane potentials and were therefore excluded from analysis. Cells were held for varying times from a few minutes to $4 \mathrm{hr} 45 \mathrm{~min}$; all of the data in this paper are derived from cells which exhibited stable membrane characteristics for at least $10 \mathrm{~min}$ after impalement, i.e., to completion of the standard protocol, and usually longer.

Data acquisition and current injection protocols were under computer control. Data were digitized with a 12-bit A/D converter (Manis and Bertrand, 1989) at a rate of $10 \mathrm{kHz}$ and prefiltered at $5 \mathrm{kHz}$. The protocol consisted of collecting responses to a series of current pulses $(100 \mathrm{msec})$ between -1 and $1 \mathrm{nA}$ in $0.1 \mathrm{nA}$ steps. If time permitted, responses to a second series of current pulses between -2 and $2 \mathrm{nA}$, in $0.2 \mathrm{nA}$ steps were also collected. Responses to current pulses were also studied as a function of the holding potential. Not all protocols were used on all cells, so quantitative measurements are available only for subsets of the total population studied. 

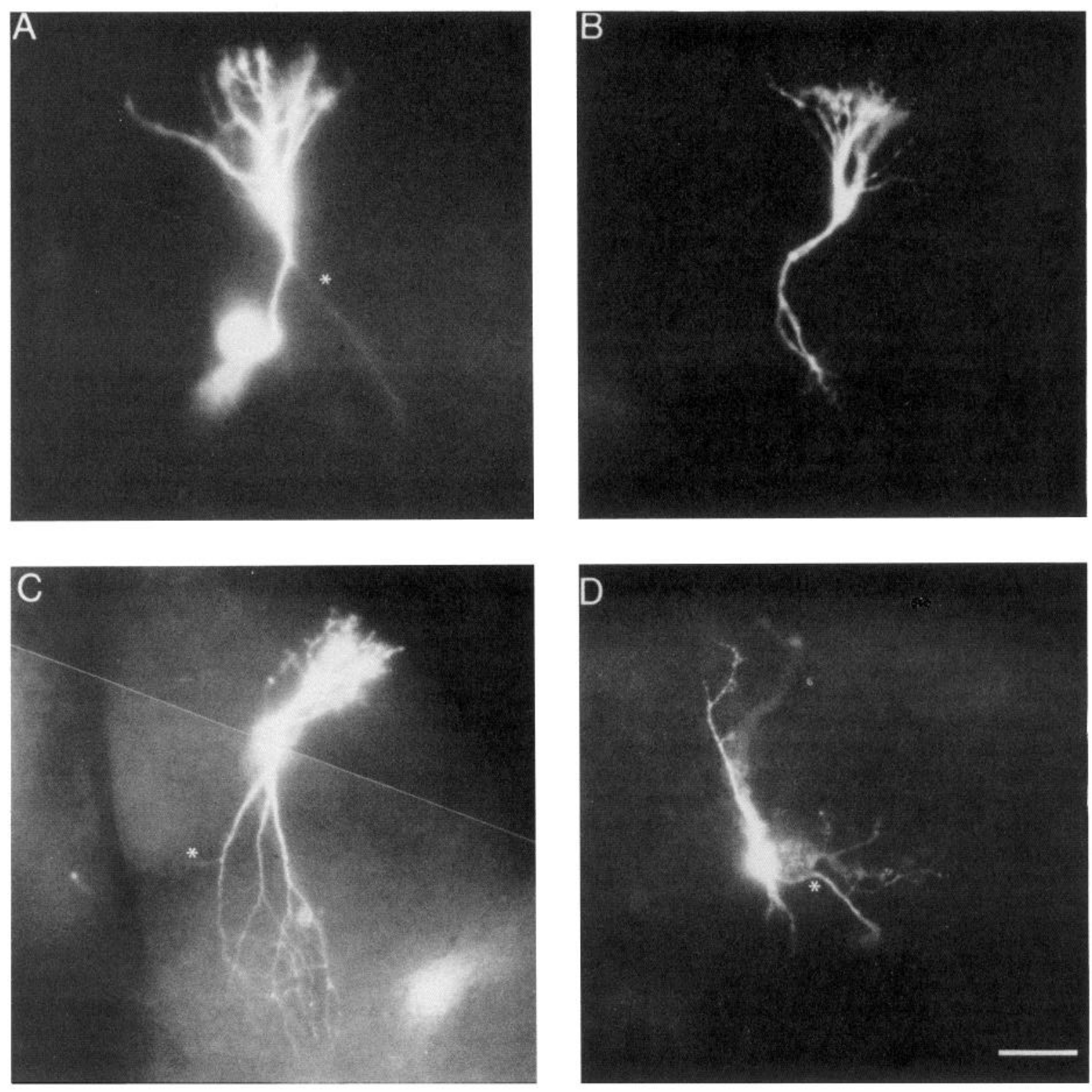

Figure 1. Three pyramidal cells and a vertical cell stained with Lucifer yellow from the guinea pig dorsal cochlear nucleus. $A$, Pyramidal cell from a strial slice. The spiny apical and smooth basal dendritic arbors can be identified. The cell axon can be seen faintly leaving the cell to the right (asterisk). No axon collaterals were identifiable. Dorsal is to the right, the lateral ependymal surface of the DCN is at the top of the photograph. $B$, Pyramidal cell from a strial slice. Branching at end of basal dendritic arbors is visible. The axon could not be identified. Orientation is the same as for the cell in $A$. C, Pyramidal cell from a transstrial slice. This cell had a more extensive basal dendritic tree. Axon leaves to the left (asterisk). The cut end of the axon can be seen to the left of the dark vertical stripe (produced by the net used to hold the slice in the chamber). A second stained pyramidal cell is out of focus in the lower right-hand corner. Rostral is at the upper left corner of the photograph, and the lateral ependymal surface of the nucleus is at the top right. $D$, "Vertical" cell from layer 3 of a strial slice. This cell has 2 main apical dendritic branches oriented nearly orthogonal to the plane of the slice (1 branch is out of focus), which reach only into layer 2 . The axon (asterisk) goes to the dorsal posterior ventral cochlear nucleus, after producing numerous local collaterals to the ventral (right) side of the cell. The lateral ependymal surface of the DCN is at the top of the picture, and ventral is to the right. Scale bar $(A-D), 100 \mu \mathrm{m}$. All cells photographed with a $10 \times$ objective in $350-\mu \mathrm{m}$-thick slices cleared with DMSO.

Data analysis. Digitized data were analyzed by computer, using the program DATAC (Bertrand and Bader, 1986). Current-voltage relations were derived for subthreshold current injections at times before the development of inward rectification (i.e., $15-35 \mathrm{msec}$ into the current pulse), and $95 \mathrm{msec}$ after the start of the $100 \mathrm{msec}$ duration pulse. The linear portion of the current-voltage relationship just below the resting potential was used to determine input resistances with a linear regression. The primary membrane time constant $\left(\tau_{0}\right.$; Rall, 1969) was estimated using a simplex nonlinear curve fit to the charging waveform at the start of a small hyperpolarizing current step. The curve fit was performed only for points at times $>3 \mathrm{msec}$ after the start of the current step, in order to minimize contributions from electrode settling and the first equalizing time constant $\tau_{1}$ (Rall, 1969).

Spike amplitudes, rise-fall slopes, and half-widths were determined by a computational algorithm. Briefly, an action potential was detected as an event which crossed a voltage threshold of $-20 \mathrm{mV}$. The peak of the action potential was then found, and the potential change between 10 and $90 \%$ peak amplitude (re: resting potential) used to determine the rising and falling slopes. The half-width was measured as the spike width at $1 / 2$ of the spike amplitude (re: resting or holding potential to spike peak), using interpolation between digitized points. The measures obtained from 4-11 spikes, either generated spontaneously or driven 

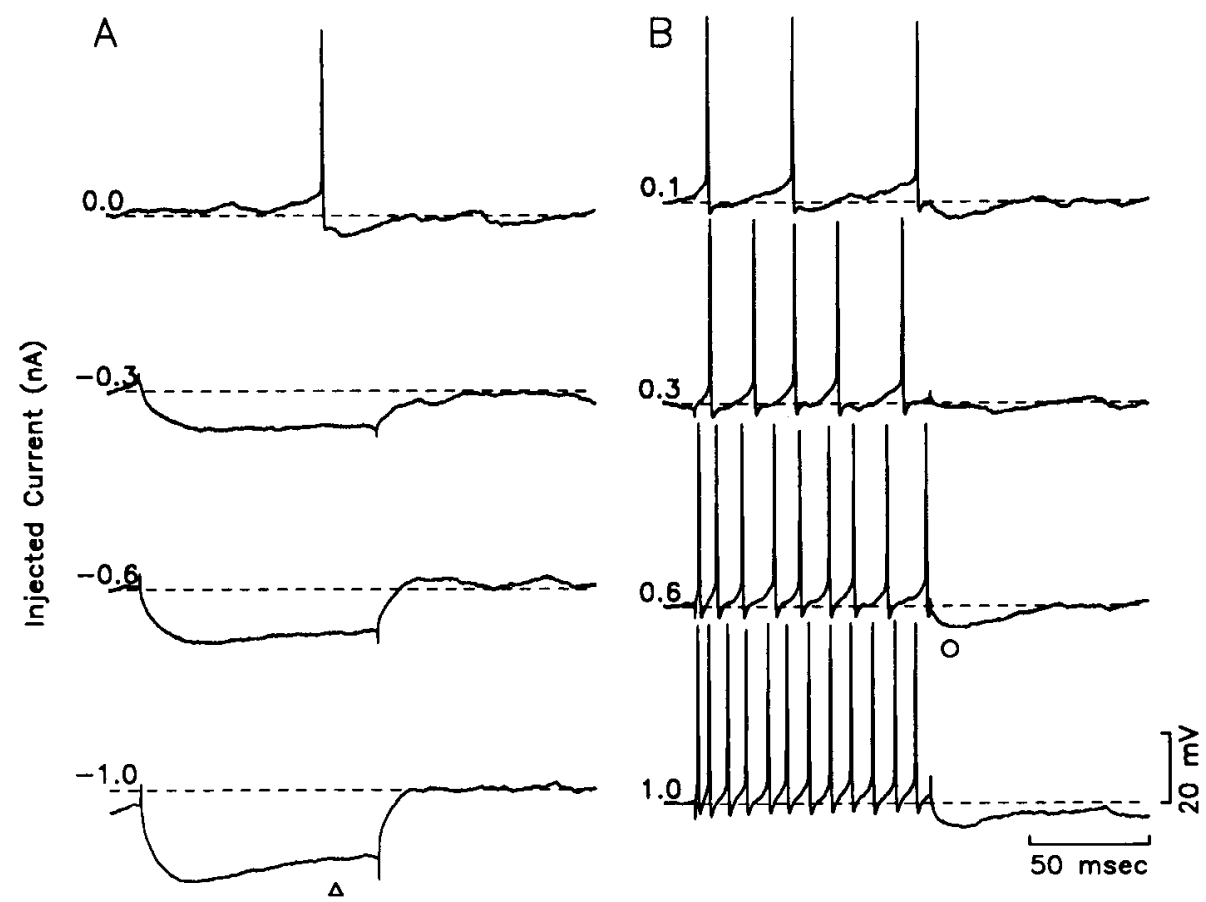

Figure 2. Responses of a simple-spiking DCN neuron to short current pulses. Responses to 100 -msec hyperpolarizing pulses and a spontaneous action potential are shown in column $A$, depolarizing pulses in column $B$, at the values indicated (in $\mathrm{nA}$ ). $A$, Hyperpolarizing pulses produce an exponential charging trajectory. At the break of the current, the membrane potential returns more rapidly to the baseline than predicted from the membrane time constant. With large hyperpolarizations, a sag in the response is seen (triangle in $-1.0 \mathrm{nA}$ trace). $B$, Depolarizing current pulses produce trains of relativcly constantinterval spikes with little adaptation. The spike burst is followed by a slow hyperpolarization (circle below $0.6 \mathrm{nA}$ trace in $B$ ). Individual action potentials exhibit a double afterhyperpolarization consisting of a fast and slow component separated by a small depolarization. Dashed lines indicate resting potential prior to delivery of the current pulse which varied between -51 and -55 $\mathrm{mV}$ for individual traces. by current injections which produced low firing rates $(<30$ spikes $/ \mathrm{sec})$, were then averaged for each cell. Spike latencies and interspike intervals (measured at an absolute membrane potential of $-20 \mathrm{mV}$ ) were also computed.

Histology. Slices which contained cells injected with Lucifer yellow (typically $-2 \mathrm{nA}$ pulses $250 \mathrm{msec}$ long delivered at a rate of $2 \mathrm{~Hz}$ ) were fixed in $5 \%$ formalin with $5 \%$ dextrose in PBS (Grace and Llinás, 1985). After $24 \mathrm{hr}$, the slices were rinsed in PBS, immersed in a drop of DMSO on a coverslip, and viewed using epi-illumination fluorescence with $10 \times 0.22 \mathrm{NA}, 25 \times 0.40 \mathrm{NA}$, and $40 \times 0.60 \mathrm{NA}$ objectives. The locations of filled cells were compared to drawings of the slice and recording locations made during the experiment in order to correlate recorded and marked cells unequivocally. Examination of the filled cell at the lowest magnification was in most cases sufficient for identification of the cell type using criteria of Lorente de Nó $(1933,1981)$, Brawer et al. (1974), and Blackstad et al. (1984). The filled cells were photographed on slide film, and the slices reimmersed in the fixative. The slices were then sectioned at $30 \mu \mathrm{m}$ and mounted using Fluomount (Gurr) for later examination of dendritic spines and fine processes under higher power.

\section{Results}

Intracellular recordings were made from $72 \mathrm{DCN}$ neurons. These cells were chosen on the basis of having resting potentials more negative than $-50 \mathrm{mV}$ and action potentials at least $50 \mathrm{mV}$ in amplitude as measured from the resting potential. In cells that were spontaneously active, determination of the resting potential was problematic, and therefore only the action potential criteria could be used. Twelve of the 72 cells exhibited complex action potential profiles similar to those shown by Hirsch and Oertel (1988a). Their responses are not discussed in this paper.

\section{Morphologically identified cells}

Eleven cells recorded in or near layer 2, and which fulfilled the physiological criteria described in the Materials and Methods and above, were filled with Lucifer yellow. Ten of these filled neurons were pyramidal cells, 3 of which are shown in Figure $1, A-C$. These cells had highly branched, spiny apical dendrites terminating near the ependymal surface of the DCN. Their basal dendrites reached into layer 3 and were devoid of spines except for the distal branches. The axon usually arose from a proximal basal dendrite (as indicated by asterisk in $A$ and $C$ ), but could also arise from the cell body and passed toward the dorsal acoustic stria. In 5 cells in which the axon could be followed as far as the striae (where it formed a bead as it reached the cut edge of the slice), no local collaterals were evident. The remaining stained cell was a layer- 3 neuron (Fig. $1 D$ ) with 2 major dendritic processes reaching up into layer 2 , and a short set of branched dendrites reaching towards layer 4 . The axon (marked by asterisk) arose from the cell body and branched locally adjacent to the cell. A single axonal process could be followed into the dorsal part of the posterior ventral cochlear nucleus. This cell appears similar to cells described by Lorente de Nó $(1933,1981)$ as vertical cells, both in the disposition of its dendritic tree and the trajectory of its axonal branches.

\section{Responses to injected current}

The responses to small hyperpolarizing current pulses $(<0.4$ nA) were characterized by approximately exponential charging trajectories. At higher current levels, a sag in the response is evident at times after $15 \mathrm{msec}$ (Fig. $2 A,-1.0 \mathrm{nA}$ trace). The membrane potential trajectory at the break of the current step often has a slightly shorter time constant than the trajectory at the start of the step and is discussed in more detail below.

The responses of a cell to depolarizing current pulses delivered from rest are shown Figure $2 B$. The cell fires a regular train of action potentials in response to the current injection. Following the trains, particularly at the higher injection levels, there is an afterhyperpolarization (Fig. $2 B$ ). The postinjection afterhyperpolarization in the simple spiking cells is generally short in duration $(\sim 50 \mathrm{msec})$ and small $(<5 \mathrm{mV})$ (see also Fig. $6, A 1$, A2).

Individual action potentials were followed by either a compound fast and slow afterhyperpolarization separated by a small depolarization (see Fig. $2 A, 0 \mathrm{nA}$ trace) or by an apparent single 

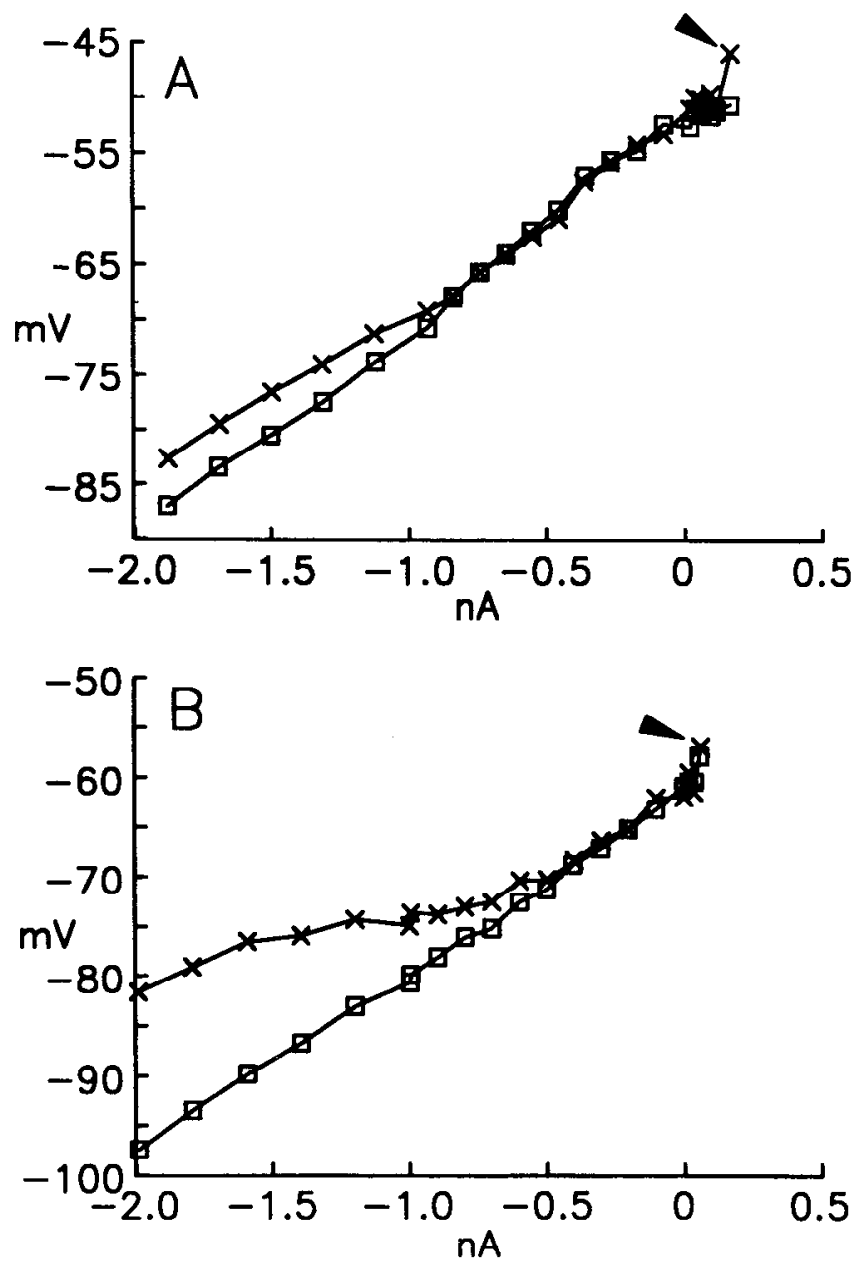

Figure 3. Subthreshold current-voltage relationships for 2 simplespiking cells. Curves marked with squares were taken $15-35 \mathrm{msec}$ into the current pulse, before the activation of the depolarizing sag. Lines marked with crosses were determined $95 \mathrm{msec}$ after the start of the current pulse. Upward deviation of the membrane potential at this late time indicates the presence of an inward rectification, which begins at a potential between 10 and $20 \mathrm{mV}$ below rest. The rectification is larger in $B$ than in $A$. Note that for small depolarizing pulses, there is an additional inward rectification, as indicated by the upward turn of the curves for positive current (arrowheads). The time course of this rectification varied between cells, developing slowly in some $(A)$ and more quickly in others $(B)$. Measurements could not be made for larger currents due to the generation of action potentials.

afterhyperpolarization with a fast onset and slow decay (see spontaneous record in Fig. $7 A$ ). All of the stained pyramidal cells and the 1 stained vertical cell were simple spiking cells with characteristics similar to those shown in Figure 2.

Several features of the passive and active properties of the simple spiking cells were quantificd for comparison with other studies. The mean resting potential in nonspontaneously active cells was $-55.5 \pm 3.1 \mathrm{mV}$ (mean $\pm \mathrm{SD}, N=28$ ). The input resistance was $27.0 \pm 16.6 \mathrm{M} \Omega(N=53)$, and the time constant was $10.2 \pm 6.0 \mathrm{msec}(N=52$; values measured at the holding potential in spontaneously active cells, at resting potential in all other cells). Action potentials had a height measured from rest (or in spontaneously active cells, the holding potential) of 61.8 $\pm 9.3 \mathrm{mV}(N=55)$ and half-widths of $0.506 \pm 0.115 \mathrm{msec}(N$ $=45)$. The slope of the rising phase $(213 \pm 62 \mathrm{mV} / \mathrm{msec}, N=$
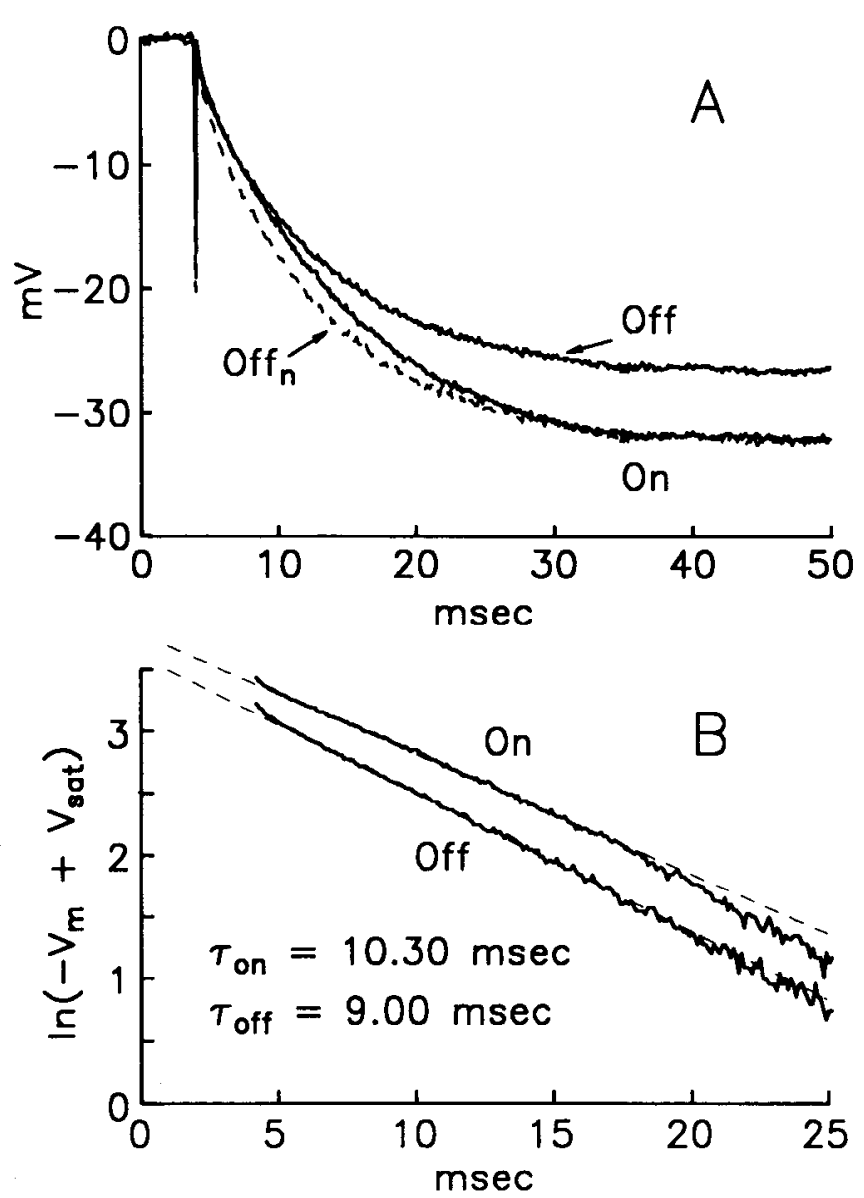

Figure 4. A, Direct comparison of voltage trajectory during onset of a current pulse ( $O n$ trace) and offset of the current ( $O f f$ traces) in a DCN cell. The response to the offset of a hyperpolarizing current pulse has been inverted for comparison with the voltage trajectory at the onset. Dashed trace marked $O f f_{n}$ is the offset trajectory normalized to the same amplitude as the voltage from the current onset. Note that the voltage trajectory during the current offset is faster than that observed during the current onset. $B$, The data in $A$ are replotted on a logarithmic voltage scale (with the saturating potential between 40 and $50 \mathrm{msec}$ subtracted) with expanded time. The voltage trajectories are nearly linear, indicating the exponential nature of the decay. The dashed lines are superimposed linear regressions over 5-15 msec (1-11 msec after the current changed). The different slopes of these lines indicate the different membrane time constants.

45) was greater than that of the falling phase $(158 \pm 42 \mathrm{mV} /$ msec, $N=45$ ).

\section{Current-voltage relationships}

The current-voltage relationships measured during hyperpolarization for 2 simple spiking cells are illustrated in Figure 3. These plots show the current-voltage relationship shortly after the onsct of the current pulse (15-25 msec, squares) and near the end of the pulse ( $95 \mathrm{msec}$, crosses). Near the pulse onset, the current-voltage relationship was approximately linear. Near pulse offset, however, some (Fig. $3 B$ ) but not all (Fig. $3 A$ ) cells showed a time and voltage-dependent sag, especially during large hyperpolarizations. This sag could appear as early as 15 msec into the current injection and could last for the duration of a $300 \mathrm{msec}$ pulse (not shown). The sag appeared between 10 and $20 \mathrm{mV}$ below rest; although in a few cells sags in response to current injection only appeared for very large hyperpolariza- 

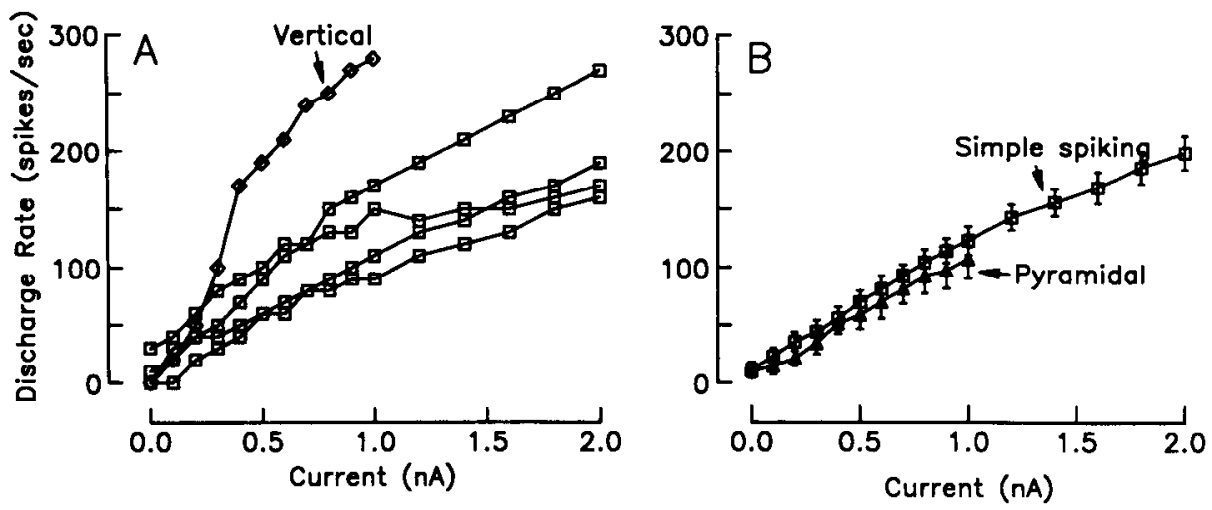

Figure 5. Firing frequency versus current injection relationship. $A$, Curves for 5 individual cells. The cell marked with diamonds was identified as a vertical cell (see text). All other cells were unidentified. Most unidentified cells showed an approximately linear relationship between firing frequency and intracellular current injection, with a mean slope of $116 \mathrm{~Hz} / \mathrm{nA} . B$, The mean current-firing frequency relationship is compared for 7 identified pyramidal cells (triangles) and 7 unidentified simple spiking cells (squares). Error bars in $B$ indicate SEM. tions $(>40 \mathrm{mV})$. Such a sag was apparent in $23 / 53$ simple spiking cells.

An additional time-dependent inward rectification was evident for small depolarizing pulses $(<0.1 \mathrm{nA})$ especially near pulse offset (Fig. 3, arrowheads). In some cells this rectification developed slowly (i.e., Fig. $3 A$ ), whereas in others it was also evident relatively early during the current step (Fig. $3 B$ ). This rectification appeared to be activated at a membrane potential just above rest and often brought the cell to threshold for action potential generation during the current pulse, even for small pulses $<0.1 \mathrm{nA}$. The generation of action potentials made it difficult to assess the current-voltage relationship to larger depolarizing pulses.

\section{Anodal break responses}

The membrane potential trajectory at the end of a hyperpolarizing pulse was often different than that at the start of the pulse. This asymmetry could take 2 different forms. As shown in Figure $4 A$, the response to the start (trace marked "On") of a hyperpolarizing step was approximately exponential. The return to the resting level at the anodal break also had an exponential shape but occurred with a time constant that was shorter than expected from the charging time constant measured at the start of the current step (dashed trace marked by "Off",).

The difference between the membrane time constants can be more directly appreciated in a log-linear plot of the membrane voltage change as shown in Figure $4 B$. The dashed lines superimposed on the transformed data are straight-line fits to the data between 1 and $11 \mathrm{msec}$ from the start of the pulse. The inverse of the slope yields the time constant, which is $10.3 \mathrm{msec}$ for the response to the hyperpolarization and $9.0 \mathrm{msec}$ for the return to rest. Similar differences were observed in other cells. The time constant difference suggests that the membrane conductance is larger at the end of the current step than at the start of the step.

In a few cases, a small $(<2 \mathrm{mV})$ overshoot of the resting level is also evident (for example, Fig. $2 A,-0.6 \mathrm{nA}$ ). However, this overshoot usually does not cross the threshold for generation of an action potential in simple spiking cells.

\section{Discharge rate versus current injection}

All simple spiking cells exhibited a monotonic increase in discharge rate with increasing depolarizing current (Fig. 5). The discharge rate was quantified as a function of current injection magnitude from the average spike count during $100 \mathrm{msec}$ current injections (such as those shown in Fig. $2 B$ ). Figure $5 A$ shows firing rate versus injected current for several individual cells. The cells marked by squares are unidentified simple spiking cells. The majority of these cells exhibit an approximately linear sensitivity to injected current that is independent of the spontaneous rate of the cells (rate at zero current). The mean slope of the current versus firing rate function was $116 \pm 37$ spikes/ $\mathrm{sec} / \mathrm{nA}$ ( $N=25$ cells studied with $<0.1 \mathrm{nA}$ holding current). The layer 3 vertical cell shown in Figure $1 D$ exhibited a much steeper relationship and 2 different firing ranges (marked by diamonds in Fig. 5,4).

Seven simple spiking cells identified as pyramidal cells by Lucifer yellow injection had discharge rate functions similar to those of unidentified simple spiking cells. This comparison is shown in Figure $5 B$ as the means of the discharge rates for 7 identified cells and 7 unidentified cells. On the basis of the discharge rate, the simple spiking cells appear to represent a relatively homogenous physiological population (with the possible exception of the vertical cell) that is similar to that of identified pyramidal cells.

\section{Adaptation properties of DCN cells}

Most cells showed little change in their interspike interval during a $1.0 \mathrm{nA}, 100 \mathrm{msec}$ depolarizing current injection, suggesting that accommodation or acceleration of discharge rate is not prevalent in DCN cells. Figure $6, A 1-A 3$ shows the discharge patterns of 3 different cells (studied with $<0.1 \mathrm{n} A$ holding current) in response to $1.0 \mathrm{nA}, 100-\mathrm{msec}$ duration depolarizing current injections. The cell in $A 1$ has a first interval which is slightly longer than the subsequent intervals. This cell therefore shows a discharge rate acceleration during the current pulse. The cell in $A 2$ shows adaptation, or a first interval, which is shorter than the subsequent intervals. The cell shown in $A 3$ has a constant discharge rate as a function of time through the current step. Nine examples (out of 24 cells analyzed) of the interspike interval, normalized to the duration of the first interval, as a function of time into the current pulse are shown in Figure $6 B$. The interspike intervals of 2 cells that showed adaptation, 3 that showed acceleration, and 4 that showed little if any rate change are shown in Figure $6 B$. Most cells (19/24) exhibit little adaptation or acceleration of the firing rate during the $100-\mathrm{msec}$ current pulse when firing is evoked from rest, while $2 / 24$ cells showed adaptation and $3 / 24$ cells showed acceleration. Qualitatively similar results were evident for spontaneously active cells studied with holding currents and for current amplitudes up to $2.0 \mathrm{nA}$. These results indicate that most DCN cells show little change in discharge rate over the $100-\mathrm{msec}$ 
Figure 6. Firing rate changes during current injection. $A$, Discharge of DCN cells in response to $100 \mathrm{msec} 1 \mathrm{nA}$ depolarizing current injection. $A I$, Cell with long first interval (arrow) relative to subsequent intervals; $A 2$, cell with short first interval (arrow); A3, cell with constant interspike intervals. Postresponse hyperpolarizations are marked with circles below the trace; cell resting potentials are shown by the dashed lines and the numeric value near the end of each trace. $B$, Interspike intervals during $100-\mathrm{msec} 1 \mathrm{nA}$ current injection for 9 example cells of 24 studied. Intervals are normalized to the first interval during the train so that cells can be compared. Most cells (4 examples shown in squares) show little accommodation or acceleration of discharge rate during the current injection. Two cells exhibited significant accommodation (deviation of ISI above 1.5; crosses), while 3 cells appeared to show significant acceleration (triangles).

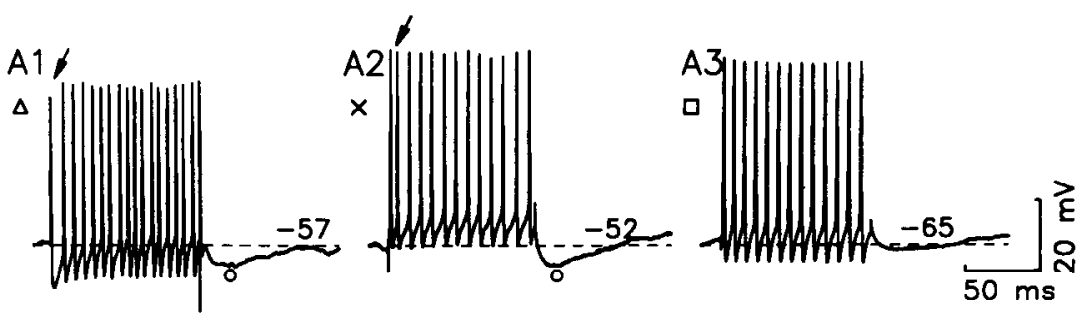

B

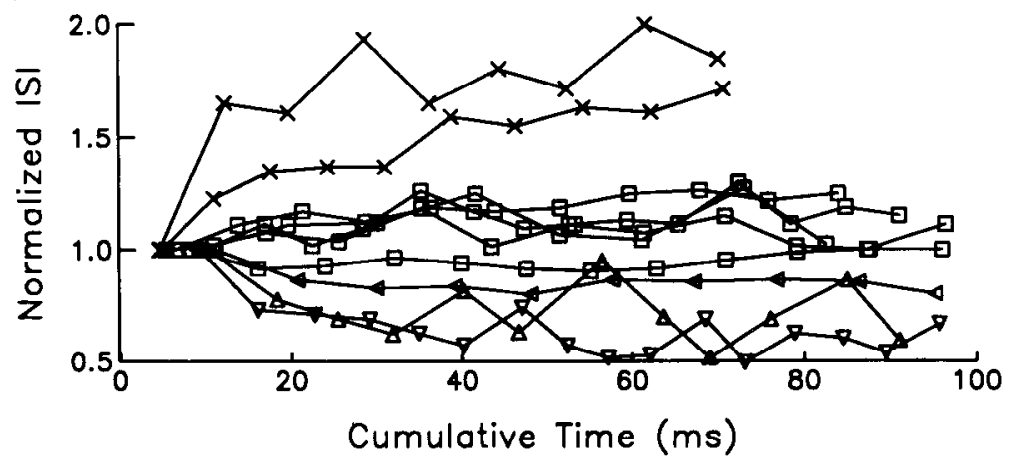

duration of the current pulse. When a rate change is evident, is usually occurs within the first $30-40 \mathrm{msec}$ of the current pulse.

\section{Changes in temporal response with bias currents}

The presence of the inward rectification with small depolarizations and polarization dependent time constants suggests that DCN cell membrane properties change with membrane potential in the region around rest. Small alterations of the resting membrane potential may therefore affect the response to imposed membrane potential changes. Figure 7 shows the response of a spontaneously discharging cell to depolarizing and hyperpolarizing current steps. Figure $7 A$, top trace, shows the spontaneous activity, with a mean firing rate of $22 \mathrm{~Hz}$; and Figure $7 B$, middle panel, shows the response to a hyperpolarizing current pulse. The spontaneous activity does not return immediately following the offset of the current pulse. Rather, there is a slow steady depolarization that develops (Fig. $7 \mathrm{~B}$, arrow) and eventually reaches threshold, after which the cell begins firing spontaneously again. Note that the recovered spontaneous rate is nearly the same as in the top panel. When the cell is depolarized during spontaneous activity, it responds with a train of spikes at a constant rate (Fig. $7 \mathrm{C}$ ). Following the current injection there is a slow hyperpolarization followed by depolarization and a gradual return of spontaneous activity. The initial rate during recovery of spontaneous firing is slightly less than that of the spontaneous rate in Figure $7 \mathrm{~A}$. In addition, the shape of the spike afterhyperpolarization differs slightly from the spontaneous spike afterhyperpolarization, in that fast and slow components (Fig. $7 C$ ) can be clearly distinguished by way of an intervening depolarization. The changes in the spike afterhyperpolarization suggest that the conductance state of the membrane differs following hyperpolarizing and depolarizing current injections.

Recordings such as those of Figure $7 B$ show that depolarizations towards rest from a hyperpolarized level can result in a transicnt $(\sim 100$ msec duration) cessation of spontaneous activity. This observation suggests that for small depolarizations, the latency to the first spike should be increased when the depolar- ization is delivered from a hyperpolarized membrane potential, relative to the same depolarization from rest. This hypothesis was tested directly by holding a cell at different hyperpolarized levels and then depolarizing the cell with a current pulsc to a constant level. The results of this type of experiment for one cell are shown in Figure 8. At rest, both a 500 pA (Fig. 8A) and $1 \mathrm{nA}$ (Fig. $8 B$ ) current pulse produced regular trains of action potentials. When the cell was hyperpolarized by about $5 \mathrm{mV}$ (A2), the latency of the response to the smaller current pulse was increased. Further hyperpolarization resulted in longer latencies, until, in $A 5$, the cell only reached threshold in 3 of 4 trials during the $100 \mathrm{msec}$ current pulse. At the less hyperpolarized holding levels, the cell fired at a regular rate once threshold was reached. This discharge rate is only slightly less than that produced by the same depolarization from rest. In contrast, for the same holding voltage, larger depolarizing current pulses generate a small fast depolarizing event, e.g., arrowhead in $B 3$ at $-66 \mathrm{mV}$, which can reach threshold for action potential generation. However, following this early event, the membrane potential falls below threshold and then gradually depolarizes until a train of regularly timed action potentials is initiated. This sequence of events creates a long first interspike interval in the cell's discharge pattern. Again, the sustained discharge rate is slightly less than that produced by the same depolarization from rest. Note also that the first spike which occurs after the pause in B3-B5 (asterisk in B3) is smaller than either the first or subsequent spikes in response to the current pulse. This attenuated action potential is also evident but not as obvious in Figure 8, A2-4 and was evident in other cells studied using the same paradigm. The first spikes after the pause were typically 2-4 mV smaller than the other evoked or spontaneous spikes, exhibited slightly greate half-widths and slightly slower rising phase slopes.

Firing patterns dependent on holding potential were observed in 17 of 21 cells tested; the remaining 4 cells always fired in a rcgular pattcrn regardless of the prior holding level. Twelve cells exhibited 3 distinct discharge patterns depending on the holding and test pulse levels: regular discharges (from rest or with $\sim 1$ 
nA depolarizing pulses), long-latency discharges (with prior hyperpolarization and 250-500 pA depolarizing test pulses), and discharge patterns characterized by long first interspike intervals (with prior hyperpolarization and 500-1000 pA depolarizing test pulses). Three of these cells were identified by Lucifer yellow injection as pyramidal cells. Four cells exhibited only the regular and long-latency discharge patterns, while 1 cell exhibited only regular and long first interspike interval discharge patterns. The failure to observe all 3 patterns in all cells may have resulted from the fixed test protocol that was used. The appropriate current injection to reach a specific depolarized or hyperpolarized voltage range will depend on the cell's input impedance. However, usually only 2 depolarizing current levels were tested in a given cell, so it is possible that different amplitude current steps might have revealed the other different discharge patterns in these cells.

Thus, some DCN cells can exhibit 3 different types of temporal responses to current injection, depending upon the preceding resting level of the cell. At rest, depolarization produces a short-latency train of regularly timed action potentials. When the membrane has been held hyperpolarized, small current pulses also produce a regular train of action potentials but with a long latency to the first spike. Larger current pulses can produce a short-latency action potential followed by a long silent interval (i.e., a long first interspike interval), and finally a regular train of spikes.

Figure 9 shows the holding potential dependence of several parameters associated with these discharge patterns. The upper panels show how these measurements are made for the longlatency discharge pattern $(A)$ and for the pattern with long first interspike intervals $(D)$. For the long-latency discharge pattern, the rate of rise of the slow depolarization (measured from the time after the membrane potential settles to its new level in response to the current pulse to just before the knee of the first spike) shows a slight dependence on the prior holding voltage with a faster rate of rise being produced with less hyperpolarized holding levels (Fig. 9B; 2 different cells shown with different symbols). Figure $9 C$ shows that the discharge latency for the long-latency response pattern is strongly influenced by the prior holding voltage over the range of -55 to $-70 \mathrm{mV}$, with little latency increase for more negative holding voltages. For responses with a long first interspike interval, Figure $9 E$ shows the relationship between the duration of the first interspike interval and the holding level. The duration of the first interspike interval increases with hyperpolarized holding levels between rest and $15 \mathrm{mV}$ below rest. In contrast, the steady-state discharge rate, measured from the second spike to the end of the current pulse, remains relatively constant or slightly increases (Fig. 9F).

\section{Discussion}

\section{Identity of recorded cells}

The electrical properties of neurons recorded from the DCN in the slice preparation fall into 2 categories: simple spiking and complex spiking cells. The simple spiking cell population includes pyramidal cells, because all of the stained and identified pyramidal cells were simple spiking cells. Vertical cells of layer 3 may also be simple spiking cells, as the only stained vertical cell fell into this category. These observations are in agreement with those of Oertel and Wu (1989), who identified 8 pyramidal cells and 2 layer- 3 multipolar cells as simple spiking cells with intracellular HRP injection. None of the pyramidal cells in the present study in which axons were identified had local collat-
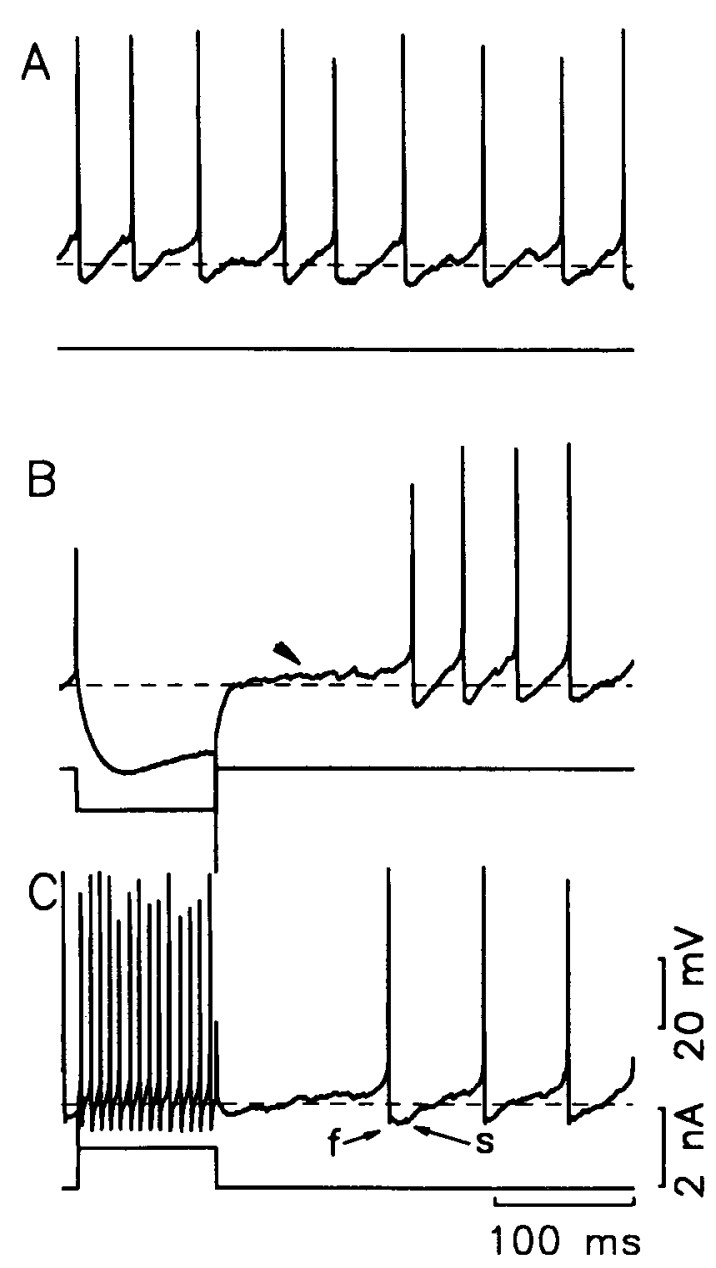

Figure 7. Effects of depolarization and hyperpolarization on spontaneous activity in simple spiking DCN cells. $A$, Spontaneous discharges of a DCN cell. Single action potentials occur with an approximately constant rate of $22 \mathrm{~Hz}$. $B$, Hyperpolarizing current pulses are followed by a cessation of spontaneous activity. However, the membrane potential slowly decreases (arrow) until spike threshold is reached, at which time the cell begins to discharge at its spontaneous rate. $C$, Depolarization by a short current pulse is also followed by a silent period whose duration depends on the magnitude and duration of the current pulse. There is a slow resumption of the spontaneous firing, but the first few intervals are longer than the spontaneous intervals. Note also that a 2-component (fast and slow separated by a depolarization) structure of the AHP is more evident following the depolarizing pulse (arrows labeled $f$ and $s$ ). Dashed line indicates arbitrary level of $-59 \mathrm{mV}$. Spike amplitudes vary because of undersampling during digitization of data.

erals. This observation is in agreement with some Golgi studies (i.e., Cajal, 1909; Lorente de Nó, 1981) and intracellularly filled cells in the mouse DCN (Oertel and $\mathrm{Wu}, 1989$ ). However, local axon collaterals have been identified from intracellularly filled pyramidal cells in the cat DCN (Rhode et al., 1983b; Rhode and Smith, 1986). Axon collaterals might not have been observed in the present study if they originated from a point well within the dorsal acoustic stria, since axons were frequently cut near the point where they entered the stria. However, in 1 cell from a strial (transverse) slice, the axon could be followed as far as the dorsalmost reach of the DCN, yet no collaterals were visible. Collaterals might also be missed if they were very thin or if diffusion of the Lucifer yellow was impeded. The overall structure of the pyramidal cells was otherwise similar to that 


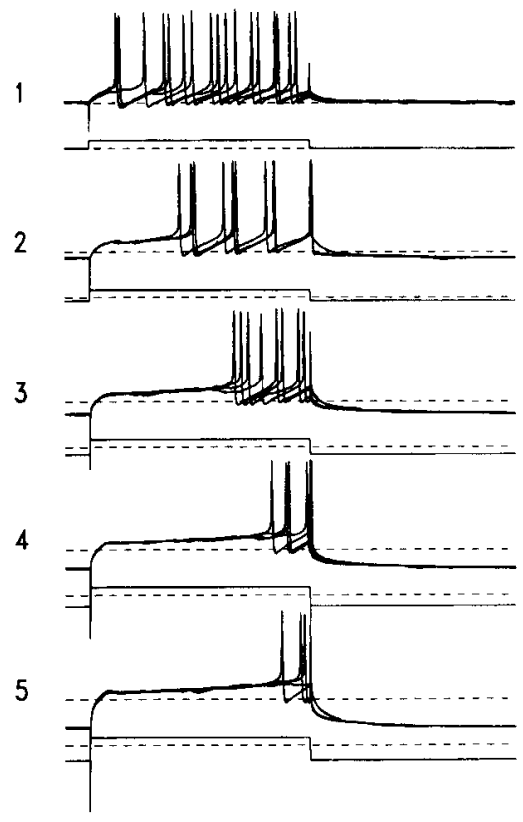

B

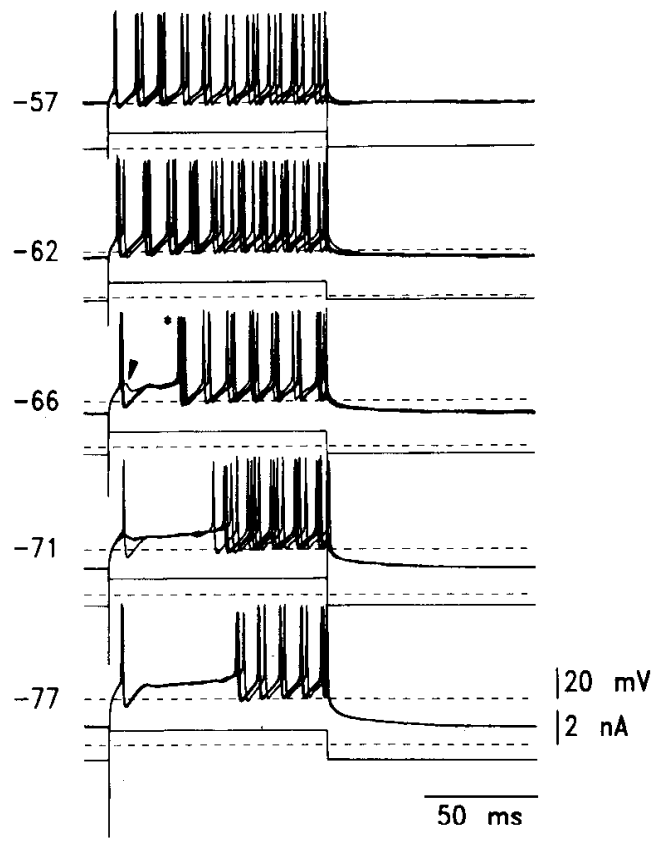

Figure 8. Effects of different levels of steady hyperpolarization on the discharge patterns produced by a step to a constant level. Records show superimposition of 3-4 traces for each stimulus condition. In column $A$, a current step to $+0.5 \mathrm{nA}$ was delivered from a series of different holding levels. With 0 holding current (i.e., $A 1,-57 \mathrm{mV}$ ), the cell discharged a regular train of action potentials. When the cell was hyperpolarized by 5 $\mathrm{mV}$, the start of the train was delayed $(A 2)$, and as the cell was hyperpolarized further, the delay to the first spike became longer $(A 3-A 5)$. With steps to $+1.0 \mathrm{nA}$ (column $B$ ), the cell discharged regularly at a higher rate. With hyperpolarization, the interval between the first and subsequent spikes increased. The first spike appeared to arise from a small fast depolarizing event (arrow in B3), which occasionally was subthreshold. The long first interspike interval was associated with a slow decrease in membrane potential until spike threshold was reached. At that point, the cell discharged a regular train of spikes, at nearly the same rate as when the same current pulse was delivered from rest $(B I)$. Note that the first spike following the pause (asterisk) is smaller than the subsequent spikes. Dashed lines indicate zero current resting potential in voltage traces ( $-57 \mathrm{mV}$ ), and zero current level in current traces.

previously described (Cajal, 1909; Lorente de Nó, 1933, 1981; Brawer et al., 1974; Kane, 1974b; Rhode et al., 1983b; Blackstad et al., 1984; Ryugo and Willard, 1985; Moore, 1986; Oertel and Wu, 1989).

Most of the cells in this report were impaled during electrode tracks made in the vicinity of layer 2 , as visually identified during the experiment. Since the stained cells obtained during these penetrations were typically pyramidal cells, it is likely that many of the unstained cells are also pyramidal cells. However, other cells found near layer 2 of the DCN may also be represented in the recordings, including cartwheel cells, stellate cells of layer 2, and some vertical cells.

\section{Physiological characteristics of DCN neurons}

The electrical properties of simple spiking neurons are in essential agreement with those reported by Hirsch and Oertel (1988a) for mouse DCN. In both studies, action potentials were obscrved to have double undershoots consisting of a fast and slow component that were sometimes separated by a small depolarization. Inward rectification was evident for membrane potentials depolarized from rest. However, the inward rectification above rest was not as obvious or as strong in the present study (e.g., Fig. 3). The relatively strong rectification reported by Hirsch and Oertel (1988a) may have been exaggerated by activation of the sodium conductance that generates action potentials, as their current-voltage plots appear to have been constructed from traces which were followed by an action potential.
In the present study, current-voltage relationships were constructed only from records that were not contaminated by action potentials either during or after the current pulse. The results, however, agree with Hirsch and Oertel (1988a) in indicating that a slowly developing subthreshold inward rectification is present in many simple spiking cells.

The most superficial 2 layers of the DCN, the pyramidal and molecular layers, exhibit a strong anatomical resemblance to the cerebellar cortex (Mugnaini et al., 1980; Lorente de Nó, 1981; Osen and Mugnaini, 1981). Within this circuit, 3 cell types are prominent: stellate cells, cartwheel cells, and pyramidal cells. The stellate cells and cartwheel cells are thought to be inhibitory interneurons (Mugnaini, 1985; Peyert et al., 1986; Wenthold et al., 1986, 1987). While the cartwheel cells are in some ways analogous to the cerebellar Purkinje cell (Mugnaini and Morgan, 1987), the pyramidal cells of the DCN are in a position somewhat analogous to that of the deep cerebellar nuclear cells. To extend this analogy, it is useful to compare the membrane characteristics of deep cerebellar nuclear cells and DCN pyramidal cells.

The properties of simple spiking DCN cells do appear somewhat similar to those of deep cerebellar nuclear neurons as described by Jahnsen (1986a) and Llinás and Mühlethaler (1988). Common properties include low resting potentials $(\sim-55 \mathrm{mV})$, relatively small action potentials $(55-60 \mathrm{mV}$, peak amplitude measured from rest), regular firing in response to depolarization from rest, similar input impedances and time constants, action 
A
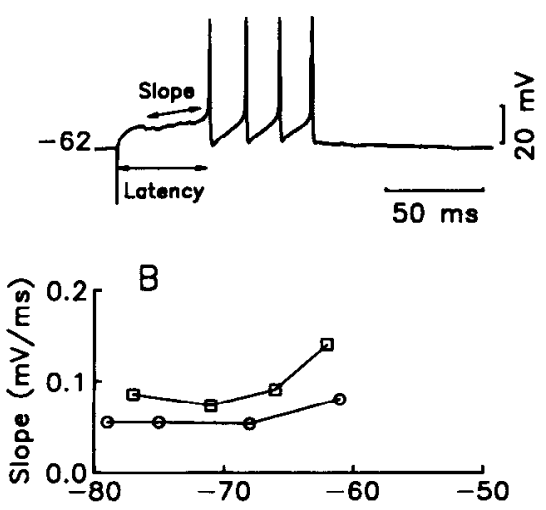

C

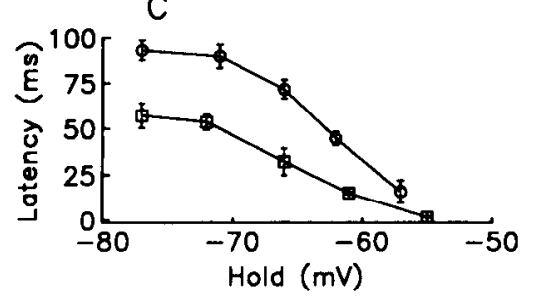

D
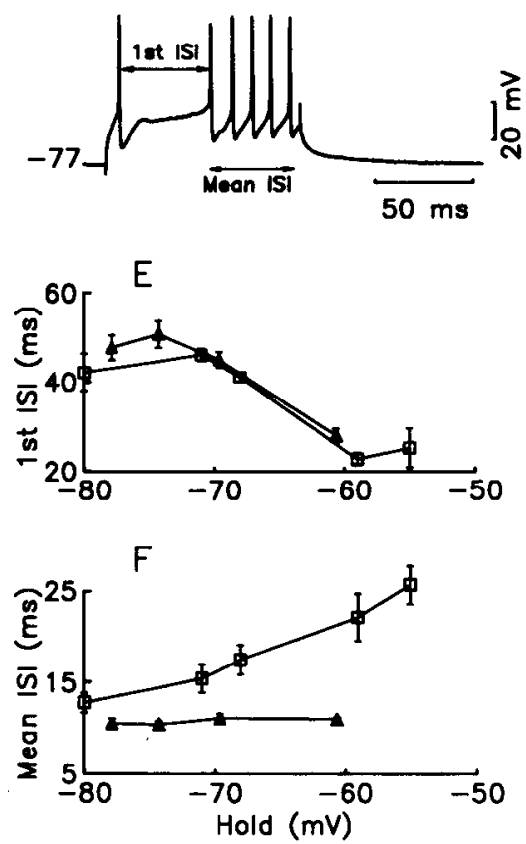

Figure 9. Voltage dependence of cell responses with hyperpolarizing holding voltages. $A$, Trace shows where measurements of membrane potential slope and first spike latency are made on cells with a long first interspike interval. $B$, Plot of the mean slope during a depolarizing step before firing commences ( 2 cells indicated by different symbols). The slope is slightly decreased by hyperpolarizing holding levels. $C$, Plot of the latency to the first spike as a function of holding level for 2 cells showing the long latency response. The latency function appears to saturate below $-70 \mathrm{mV}$. $D$, Trace shows where measurements of the first interspike interval and the mean interspike interval are made on cells with long first interspike intervals. $E$, Plot of the first interspike interval as a function of prior holding potential for 2 cells with long first interspike intervals. The first interspike interval increases with increasing hyperpolarization. $F$, Plot of the steady-state interspike interval as a function of the prior holding level for the same 2 cells as in $E$. In 1 cell, intervals are slightly but not significantly longer with prior hyperpolarization, while in the other cell, the intervals became shorter with prior hyperpolarization. The holding potentials for the examples in $A$ and $D$ are shown to the left of the traces. Error bars in $C, E$, and $F$ indicate SDs for 4 trials in each cell.

potentials with 2 component afterhyperpolarizations, evidence of a slow inward conductance just depolarized to rest, and demonstrable calcium spikes in the presence of TTX (in DCN; Hirsch and Oertel, 1988a). In addition, a high proportion of spontaneously active cells were seen both in the deep cerebellar nucleus and the present study. However, the properties of the 2 sets of cells are not identical. The rates of rise of DCN action potentials were slower than those of deep cerebellar nuclear cells by nearly a factor of 2 . Part of this difference may be attributed to the different recording temperatures used in the 2 studies (31$33^{\circ} \mathrm{C}$ vs. $36.5^{\circ} \mathrm{C}$ in Jahnsen, $1986 \mathrm{a}$ ). The persistent sodium conductance in DCN cells is normally not strong enough to generate the plateau potentials reported for deep cerebellar nuclear neurons (Jahnsen, 1986a; Llinás and Mühlethaler, 1988). Also, anodal brcak or rebound responses longer than $10 \mathrm{mscc}$ in duration due to low-threshold calcium conductances are weak or absent in simple spiking DCN cells, whereas such responses were a significant component of deep cerebellar nuclear neuron responses (Llinás and Mühlethaler, 1988).

\section{Membrane conductances underlying discharge patterns}

It is instructive to consider the characteristics of the voltagedependent membrane conductances (in addition to the fast inactivating sodium channels and delayed rectifier that generate the fast action potential) that might underlie the generation of the different DCN discharge patterns. The recordings indicate that a slow depolarization develops for small depolarizing current injections (Figs. 8A, 9A). In a previous study, Hirsch and Oertel (1988a) indicated that a similar inward rectification could be blocked by the application of $1 \mu \mathrm{M}$ TTX, which suggests that it is produced by a slow voltage-dependent sodium current. If this is the case, then Figures 7, 8, and $9 C$ suggest that this conductance is normally partially enabled at rest since the first spike latency is greatly increased by a small steady-state hyperpolarization. Further, it appears that this conductance inactivates with a shallow voltage sensitivity for membrane hyperpolarizations in the range between rest and $20 \mathrm{mV}$ below rest (i.e., -55 to $-75 \mathrm{mV}$ ). An unusual feature of the currents underlying the slow depolarization is that they appear to turn off rapidly (within milliseconds) following repolarization of the membrane after either sustained depolarizations or after an action potential (i.e., Fig. 8, $A 3-A 5$ ). The slow depolarization is not followed by plateau potentials such as are produced by a presumably similar conductance in cerebellar Purkinje cells (Llinás and Sugimori, 1980) or in deep cerebellar nuclear neurons (Jahnsen, 1986a, b; Llinás and Mühlethaler, 1988). One alternate explanation for this depolarizing ramp is that it represents a normal component of the fast-inactivating sodium conductance where the steady-state activation and inactivation curves ( $m_{\infty}$ and $h_{\infty}$ parameters of Hodgkin and Huxley, 1952) have increased overlap, i.e., the inactivation curve is shifted to more depolarized levels, while the activation curve is shifted to slight- 
ly hyperpolarized levels. A slow activation can then occur if the activation time constant is steeply voltage-dependent, with a long time constant at voltages near and just above rest and a shorter time constant at more depolarized voltages. Yet another explanation for the depolarizing ramp is that it is the consequence of inactivation of an outward potassium current. For example, a steady-state hyperpolarization might deinactivate a transient outward conductance, which would then be available for activation by subsequent depolarization. Following depolarization, this conductance would pull the membrane potential slightly more negative, and as the conductance turns off, the membrane potential would slowly depolarize. Without further pharmacologic manipulations, it is not possible to determine which of these conductance changes might be responsible for the depolarizing ramp and long-latency responses.

An additional conductance may be needed to produce either the early action potentials or the pause generated in response to stronger stimuli as shown Figure $8 B$. Some of the characteristics of this conductance may be suggested from the underlying subthreshold response that is evident when there is failure of the first action potential (Fig. 8, B3, B4). The subthreshold response consists of an early voltage-dependent fast "hump" followed by a slower "sag." Two scenarios may be entertained. In the first, the early "hump" could be generated by an active membrane conductance, such as a rapidly inactivating lowthreshold calcium conductance (Llinás and Yarom, 1981). A second scheme suggests that the "sag" after the hump is generated by an active conductance, such as a transient (" $A$ ") potassium conductance (Connor and Stevens, 1971), and that the hump itself is part of the passive response of the cell. The slow depolarization after the hump would then be due primarily to inactivation of a transient potassium conductance and possible activation of the slow inward conductance. The "hump-sag" voltage profile with depolarization appears similar to a transient hyperpolarization that is TTX, $\mathrm{Co}^{2+}, 4-\mathrm{AP}$, and $\mathrm{Cs}^{+}$resistant as described in turtle cerebellar Purkinje cells by Hounsgaard and Midtgaard (1988). However, the time course of this event is about an order of magnitude faster in DCN cells.

From these considerations, it appears that a single transient potassium conductance might provide a parsimonious explanation for both the long-latency and long first interval response patterns. Such transient potassium conductances are often sensitive to 4-AP, and DCN cells do possess 4-AP-sensitive conductances (Hirsch and Oertel, 1988a; P. B. Manis, unpublished observations). The behavior of the membrane potential trajectory and the regularity of the action potential train once a threshold is reached are qualitatively consistent with prior descriptions of how such transient potassium conductances should affect cell response patterns (Connor and Stevens, 1971; Connor et al., 1977). A 4-AP-sensitive conductance appears to be responsible for long first interspike intervals associated with prior membrane hyperpolarization in mammalian tectal neurons (LopezBarneo and Llinás, 1988), although there is a concomitant reduction in the amplitude of the first action potential, which is not seen in DCN cells. Indeed, in DCN cells, the second spike is the smallest, while in tectal cells it is the largest. In addition, it is likely that in the voltage range where the response patterns are sensitive to prior membrane potential that other membrane conductances such as the slow inward current also play an important role. The identification and characterization of the currents underlying the discharge patterns of these cells clearly requires further careful study.

\section{Generation of firing patterns in DCN cells}

The firing patterns of DCN neurons in vivo are diverse and have been previously presumed to reflect synaptic events occurring in the complex neuropil of the DCN or its various afferent systems. The observations made with intracellular recordings in the slice preparation suggest that the intrinsic properties of at least some DCN cells give them the capability to discharge in different temporal patterns depending upon their resting level. The temporal patterns observed in vitro show a similarity to the "pauser," "buildup," and "chopper" patterns reported for DCN cells in vivo. That all 3 patterns can be generated by a single cell is consistent with prior observations that a single DCN unit can exhibit different discharge patterns depending on the stimulus conditions (Goldberg and Brownell, 1973; Godfrey et al., 1975; Adams, 1976; Rhode and Kettner, 1987). These 3 patterns can be obtained with intracellular manipulation of the membrane potential of a single cell that lacks local axonal collaterals, so the discharge pattern of the cell is independent from recurrent synaptic events. Thus, it may not be necessary to invoke complex synaptic interactions (feedforward inhibition: Kanc, 1974a; presynaptic inhibition: Britt and Starr, 1976) or recordings some distance from the site of action potential generation (Gerstein et al., 1968; Starr and Britt, 1970) to explain the generation of some DCN temporal response patterns, although clearly synaptic inputs are necessary to drive these patterns.

Further support for the involvement of intrinsic membrane properties in the generation of DCN cell responses stems from the intracellular studies of Rhode et al. (1983b, 1986). In some DCN cells in vivo, they found that it was possible to change the response pattern of the cell to acoustic stimuli from a "chopper" to a "pauser" or "buildup" by hyperpolarizing with current the cell membrane potential. This observation could be interpreted in 2 ways. First, the hyperpolarization may have permitted a weak inhibitory input to become more effective (by moving the cell away from the spike threshold), thereby inducing a lull in the cell discharge during a tone burst. Sccond, the hyperpolarization may have changed the ensemble of membrane conductances either available for activation or inactivated at the new membrane potential. While the present results support the latter interpretation, they do not exclude a role for inhibitory synaptic events in the generation of the discharge patterns in vivo.

Two factors will affect the firing patterns of DCN cells differently in vivo than in vitro. First, in vivo there is likely to be a greater amount of synaptic noise in the membrane potential due to spontaneous activity in afferent neurons. Depending on the afferent discharge rates, the amplitudes of individual synaptic events, and the amount of afferent convergence, the membrane noise can produce either an increase or a decrease in the variability of interspike intervals. Low afferent rates with large synaptic events should generate an increase in the variability of the interspike interval distribution (Calvin and Stevens, 1968) duc to fluctuations in the time at which the membrane potential actually achieves the threshold voltage. Thus, while the cells in slices are highly regular in their discharge, the effects of the membrane conductances on the cell discharge patterns will be somewhat less obvious in vivo than shown here. In particular, the responses shown in Figure 8 for small depolarizations from a hyperpolarized level will be very sensitive to small fluctuations in membrane potential, since the rate of rise of the membrane potential during the activation of the slow depolarizing conductance is rather slow $(0.05-0.10 \mathrm{mV} / \mathrm{msec}$; Fig. 9). The slow 
rise, coupled with synaptic noise, will lead to a greater variability of first spike latencies than would be suggested by the data from the slice. This effect can be appreciated by examining the effects of spontaneous IPSPs on the latencies of first spikes in Figure 8 , traces $A 3, A 4$, and $B 4$. Similarly, the chopping suggested by the regularity of subsequent intervals may not be evident in vivo with standard PSTH analysis because of wide variability in the latency to the first spike. Nonetheless, some tendency toward chopping during the later part of the cell discharge has been noted (Rhode and Kettner, 1987). Analysis of interspike intervals by the method of Young et al. (1988) should reveal an underlying regularity.

A second difference between the in vivo and in vitro conditions arises from the shape of the synaptic current injection produced by acoustic stimuli. The synaptic current in response to a tone burst at the cell's CF should have an early peak, corresponding to the high firing rate at the onset transient of auditory nerve fibers (Kiang et al., 1965; Smith and Brachman, 1980), followed by a lower steady-state level. This pattern should increase the probability of discharge at the beginning of the tone burst since the early peak in injected current should depolarize the cells above the steady-state level. For intense tones which produce a significant depolarization of the cell, the early peak should reinforce the "hump," resulting in a high probability of discharge at the onset of the stimulus. However, an onset peak seems to be absent in intracellular recordings from DCN cells in vivo (Gerstein et al., 1968; Romand, 1978; Rhode et al., 1983b, 1986). It is possible that this early peak is reduced in amplitude by the relatively long membrane time constant of these cells and by low-pass filtering from the cable characteristics of their basal dendrites, where the auditory nerve fibers synapse (Osen, 1970; Cohen et al., 1972; Kane, 1974a; Manis and Brownell, 1983; Moore, 1986). Another possibility is that a significant part of the excitatory input to the pyramidal cells derives from the granule cell-parallel fiber system (Mugnaini et al., 1985; Manis, 1989). Unfortunately, the acoustic response properties of this system are unknown, although input through this system may be delayed relative to that of the eighth nerve because of the fine caliber of the unmyelinated parallel fibers (Osen and Mugnaini, 1981) and their slow conduction velocity (Manis, 1989).

The discharge patterns commonly associated with DCN cells in vivo in barbiturate-anesthetized animals are rarely seen in unanesthetized decerebrate preparations (i.e., Evans and Nelson, 1973; Young and Brownell, 1976; Shofner and Young, 1985). The differences in discharge patterns are probably due to a greater activity of inhibitory interneurons in the absence of anesthesia. Similarly, the nonmonotonic rate-intensity functions of DCN cells are likely to be mediated by inhibitory events (Voigt and Young, 1980; Caspary et al., 1987), since the discharge rate of simple spiking cells is linearly related to the injected current and shows no signs of nonmonotonic behavior (Fig. 5).

\section{Significance for temporal coding by DCN cells}

The chief effect of the intrinsic membrane conductances of DCN cells is to introduce silent episodes into the discharge pattern during membrane depolarizations that follow a hyperpolarization. These conductances therefore can enhance or reinforce the cffccts of synaptic inhibition or spikc train afterhyperpolarizations. The intrinsic conductances can cause the effects of an inhibitory input to outlast both the synaptic current and the resultant synaptic potential by as long as $100 \mathrm{msec}$ (e.g., Fig. $7 B$ ). DCN cells should therefore exhibit strong temporal nonlinearities or stimulus history sensitivity which makes the prediction of responses to complex stimuli from simple stimulus paradigms much more difficult. Such nonlinearities should be particularly evident for dynamic acoustic stimuli. For example, a swept tone of constant intensity which moves from within an inhibitory region of the type IV receptive field (Evans and Nelson, 1973; Young and Brownell, 1976) to an excitatory region (and stays fixed thereafter) would be predicted to generate a buildup or pauser type of response pattern (depending on the intensity of the tone and the cell resting potential), whereas a pure tone stimulus delivered only in the excitatory area would result in a regular (chopping) discharge pattern.

The dependence of the discharge pattern on the cell membrane potential is yet another example in the $\mathrm{DCN}$ where responses depend on prior activity. Other examples include tetanic and posttetanic potentiation in the parallel fiber synapse onto DCN cells (Manis, 1989) which can modify synaptic transmission through the parallel fiber system for minutes, and the voltagedependence of synaptic events (Hirsch and Oertel, 1988b) in which membrane depolarization can increase the duration of an EPSP. Thus, both at the synaptic level and at the membrane level, the mechanisms of information processing in the DCN exhibit pronounced temporal nonlinearities.

\section{Summary}

Cells of the guinea pig dorsal cochlear nucleus have been examined with intracellular recording in an in vitro brain slice preparation. Cells could be divided into simple and complex spiking cells. Simple spiking cells, which included identified pyramidal cells, had membrane characteristics similar (but not identical) to those of deep cerebellar nuclear neurons and showed little adaptation or acceleration of discharge rate in response rate to $100 \mathrm{msec}$ current pulses. Steady-state hyperpolarization of simple spiking DCN cells could change their response to a subsequent depolarization, resulting in either a long latency to the first spike or a long first interspike interval. Three different discharge patterns (long latency, long first interspike interval, and regular) could be evoked in a single cell. Such responses are similar to the discharge patterns of DCN cells that have been recorded in vivo in response to tone bursts in anesthetized cats. These results indicate that the intrinsic membrane conductances of DCN cells may contribute to the generation of the temporal discharge patterns seen in response to acoustic stimuli in vivo.

\section{References}

Adams JC (1976) Single unit studies on the dorsal and intermediate acoustic striae. J Comp Neurol 170:97-106.

Bertrand D, Bader CR (1986) DATAC: a multipurpose biological data analysis program based on a mathematical interpreter. Int J Biomed Comput 18:193-202.

Blackstad TW, Osen KK, Mugnaini E (1984) Pyramidal neurones of the dorsal cochlear nucleus: a Golgi and computer reconstruction study in cat. Neuroscience 13:827-854.

Brawer JR, Morest DK, Kane EC (1974) The neuronal architecture of the cochlear nucleus of the cat. $J$ Comp Neurol 155:251-300.

Britt R, Starr A (1976) Synaptic events and discharge patterns of cochlear nucleus cells. I. Steady-frequency tone bursts. J Neurophysiol 39:162-178.

Cajal SR (1909) Histologie du systeme nerveux de l'homme et des vertebres, Vol 1. Paris: Malione.

Calvin WH, Stevens CF (1968) Synaptic noise and other sources of randomness in motoneuron interspike intervals. J Neurophysiol 31: $574-587$. 
Caspary DM, Paraza KE, Kossl M, Faingold CL (1987) Strychnine alters fusiform cell output from the dorsal cochlear nucleus. Brain Res 417:273-282.

Cohen ES, Brawer JR, Morest DK (1972) Projections of the cochlea to the dorsal cochlear nucleus in the cat. Exp Neurol 35:470-479.

Connor JA, Stevens CF (1971) Voltage clamp studies of a transient outward membrane current in gastropod neural somata. J Physiol (Lond) 312:21-30.

Connor JA, Walter D, McKown R (1977) Neural repetitive firing. Modifications of the Hodgkin-Huxley axon suggested by experimental results from crustacean axons. Biophys J 18:81-102.

Evans EF, Nelson PG (1973) The responses of single neurones in the cochlear nucleus of the cat as a function of their location and the anaesthetic state. Exp Brain Res 17:402-427.

Gerstein GL, Butler RA, Erulkar SD (1968) Excitation and inhibition in cochlear nucleus. I. Tone-burst stimulation. J Neurophysiol 31: $526-536$.

Godfrey DA, Kiang NY-S, Norris BE (1975) Single unit activity in the dorsal cochlear nucleus of the cat. J Comp Neurol 162:269-284.

Goldberg JM, Brownell WE (1973) Discharge characteristics of ncurons in anteroventral and dorsal cochlear nuclei of cat. Brain Res 64: $35-54$.

Grace AA, Llinás R (1985) Morphological artifacts induced in intracellularly stained neurons by dehydration: circumvention using rapid dimethyl sulfoxide clearing. Neuroscience 16:461-475.

Hirsch JA, Oertel D (1988a) Intrinsic propertics of neurones in the dorsal cochlear nucleus of mice in vitro. J Physiol (Lond) 396:535548 .

Hirsch JA, Oertel D (1988b) Synaptic connections in the dorsal cochlear nucleus of mice, in vitro. J Physiol (Lond) 396:549-562.

Hodgkin AL, Huxley AF (1952) A quantitative description of membrane current and its application to conduction and excitation in nerve. J Physiol (Lond) 117:500-544.

Hounsgaard J, Midtgaard J (1988) Intrinsic detcrminants of firing pattern in Purkinje cells of the turtle cerebellum in vitro. J Physiol (Lond) 402:731-749.

Jahnsen $\mathrm{H}$ (1986a) Electrophysiological characteristics of neurones in the guinea-pig deep cerebellar nuclei in vitro. J Physiol (Lond) 372: 129-147.

Jahnsen H (1986b) Extracellular activation and membrane conductances of neurones in the guinea-pig deep cerebellar nuclei in vitro. $\mathbf{J}$ Physiol (Lond) 372:149-168.

Jones DR, Casseday JH (1979) Projections of auditory nerve in the cat as seen by anterograde transport methods. Neuroscience 4:12991313.

Kane ES (1974a) Patterns of degeneration in the caudal cochlear nucleus of the cat after cochlear ablation. Anat Rec 179:67-92.

Kanc ES (1974b) Synaptic organization in the dorsal cochlcar nuclcus of the cat: a light and electron microscopic study. J Comp Neurol 155:301-330.

Kiang NY-S, Watanabe T, Thomas EC, Clark LF (1965) Discharge patterns of single fibers in the cat's auditory nerve. Cambridge, MA: MIT Press.

Llinás RR (1988) The intrinsic electrophysiological properties of mammalian neurons: insights into central nervous system function. Science 242:1654-1664.

Llinás R, Mühlethaler M (1988) Electrophysiology of guinea-pig cerebellar nuclear cells in the in vitro brain stem-cerebellar preparation. J Physiol (Lond) 404:241-258.

Llinás R, Sugimori M (1980) Electrophysiological properties of in vitro Purkinje cell somata in mammalian cerebellar slices. J Physiol (Lond) 305:171-195.

Llinás RR, Yarom Y (1981) Properties and distribution of ionic conductances generating electroresponsiveness of mammalian inferior olivary neurones in vitro. J Physiol (Lond) 315:569-584.

Lopez-Barneo J, Llinás R (1988) Electrophysiology of mammalian tectal neurons in vitro. I. Transient ionic conductances. J Neurophysiol 60:853-868.

Lorente de Nó R (1933) Anatomy of the eighth nerve. III. General plan of structure of the primary cochlear nuclei. Laryngoscope 33: 327-350.

Lorente de Nó R (1981) The primary acoustic nuclei. New York: Raven.

Manis PB (1988a) Intracellular recordings from pyramidal cells of the guinea pig dorsal cochlear nucleus. J Neurosci Methods 24:201.
Manis PB (1988b) Intracellular recordings from dorsal cochlear nucleus neurons in vitro. Soc Neurosci Abstr 14:694.

Manis PB (1989) Responses to parallel fiber stimulation in the guinea pig dorsal cochlear nucleus in vitro. J Neurophysiol 61:149-161.

Manis PB, Bertrand D (1989) A fast inexpensive analog-to-digital converter board for IBM PC-AT or compatible. J Ncurosei Methods $30: 41-54$.

Manis PB, Brownell WE (1983) Synaptic organization of eighth nerve afferents to the cat dorsal cochlear nucleus. J Neurophysiol 50:11561181.

Moore JK (1986) Cochlear nuclei: relationship to the auditory nerve. In: Neurobiology of hearing: the cochlea (Altschuler RA, Hoffman DW, Bobbin RP, eds), pp 283-301. New York: Raven.

Mugnaini E (1985) GABA neurons in the superficial layers of the rat dorsal cochlear nucleus: light and electron microscopic immunocytochemistry. J Comp Neurol 235:61-81.

Mugnaini E, Morgan JI (1987) The neuropeptide cerebellin is a marker for two similar neuronal circuits in rat brain. Proc Natl Acad Sci USA 84:8692-8696.

Mugnaini E, Osen KK, Dahl A-L, Freidrich VL, Kortc G (1980) Finc structure of granule cells and related interneurons (termed Golgi cells) in the cochlear nuclear complex of cat, rat and mouse. J Neurocytol 9:537-570.

Oertel D (1983) Synaptic responses and electrical properties of cells in brain slices of the mouse anteroventral cochlear nucleus. J Neurosci 3:2043-2053.

Oertel D, Wu SH (1989) Morphology and physiology of cells in slice preparations of the dorsal cochlear nucleus of mice. J Comp Neurol 283:228-247.

Osen KK (1970) Course and termination of the primary afferents in the cochlear nuclei of the cat. An experimental anatomical study. Arch Ital Biol 108:21-61.

Osen KK, Mugnaini E (1981) Neuronal circuits in the dorsal cochlear nucleus. In: Neuronal mechanisms in hearing (Syka J, Aitken L, cds), pp 119-125. New York: Plenum.

Peyert D, Geffard M, Aran J-M (1986) GABA immunoreactivity in the primary nuclei of the auditory central nervous system. Hear Res 23:115-121.

Pfeiffer RR (1966) Classification of response patterns of spike discharges for units in the cochlear nucleus: tone burst stimulation. Exp Brain Res 1:220-235.

Rall W (1969) Time constants and electrotonic length of membrane cylinders and neurons. Biophys J 9:1483-1508.

Rhode WS, Kettner RE (1987) Physiological study of neurons in the dorsal and posteroventral cochlear nucleus of the unanesthetized cat. J Neurophysiol 57:414-442.

Rhode WS, Smith PH (1986) Physiological studies of neurons in the dorsal cochlear nucleus of the cat. J Neurophysiol 56:287-307.

Rhode WS, Oertel D, Smith PH (1983a) Physiological response properties of cells labeled intracellularly with horseradish peroxidase in the cat ventral cochlear nucleus. J Comp Neurol 213:448-463.

Rhode WS, Smith PH, Oertel D (1983b) Physiological response properties of cells labeled intracellularly with horseradish peroxidase in cat dorsal cochlear nucleus. J Comp Neurol 213:426-447.

Rouiller EM, Ryugo DK (1984) Intracellular marking of physiologically characterized cells in the ventral cochlear nucleus of the cat. $J$ Comp Neurol 225:167-186.

Romand R (1978) Survey of intracellular recording in the cochlear nucleus of the cat. Brain Res 148:43-65.

Ryugo DK, Willard FH (1985) The dorsal cochlear nucleus of the mouse: a light microscopic analysis of neurons that project to the inferior colliculus. J Comp Neurol 242:381-396.

Shofner WP, Young ED (1985) Excitatory/inhibitory response types in the cochlear nucleus: relationships to discharge patterns and responses to electrical stimulation of the auditory nerve. J Neurophysiol 54:917-939.

Smith RS, Brachman ML (1980) Operating range and maximum response of single auditory nerve fibers. Brain Res 184:499-505.

Van Gisbergen JAM, Grashuis JL, Johannesma PIM, Vendrik AJH (1975) Spectral and temporal characteristics of activation and suppression of units in the cochlear nuclei of the anesthetized cat. Exp Brain Res 23:367-386.

Starr A, Britt R (1970) Intracellular recordings from cat cochlear nucleus during tone stimulation. J Neurophysiol 33:137-147.

Voigt HF, Young ED (1980) Evidence of inhibitory interactions be- 
tween neurons in dorsal cochlear nucleus. J Neurophysiol 44:76-96. Wenthold RJ, Zempel JM, Parakkal KA, Reeks KA, Altschuler RA (1986) Immunocytochemical localization of GABA in the cochlear nucleus of the guinea pig. Brain Res 380:7-18.

Wenthold RJ, Huie D, Altschuler RA, Reeks KA (1987) Glycine immunoreactivity localized in the cochlear nucleus and superior olivary complex. Neuroscience 22:897-912.

Wu SH, Oertel D (1984) Intracellular injection with horseradish peroxidase of physiologically characterized stellate and bushy cells in slices of mouse anteroventral cochlear nucleus. J Neurosci 4:15771588.

Young ED, Brownell WE (1976) Responses to tones and noise of single cells in dorsal cochlear nucleus of unanesthetized cats. J Neurophysiol 39:282-300.

Young ED, Robert J-M, Shofner WP (1988) Regularity and latency of units in ventral cochlear nucleus: implications for unit classification and generation of response properties. J Neurophysiol 60:1-29. 